\title{
Effect of Polypropylene Fiber on Shear Strength Parameters of Sand
}

\author{
Ahmad Darvishi, Ayfer Erken \\ Civil Engineering Department, Istanbul Technical University \\ İTÜ Ayazağa Campus 34469 Maslak, Istanbul, Turkey \\ darvishi@itu.edu.tr; erken@itu.edu.tr
}

\begin{abstract}
The principle of reinforced soil with fiber can be defined as a soil layer mass which includes randomly distributed discrete components, i.e. fibers, that supply on improvement in the engineering properties and mechanical behavior of the soil matrix. In this study, the effect of fiber reinforcement on shear strength parameters of sand was evaluated. In order to determine the shear strength parameters of unreinforced and reinforced sand specimen, the direct shear test was conducted. While the type of sand and fiber is kept constant, the effect of various percentages of polypropylene fiber on shear strength parameters of sand was tested in the laboratory. The main aim is to find the influence of fiber inclusion on the shear strength of dense sand specimens. For the experimental study of the research, polypropylene fiber with different percentage of $0.1 \%, 0.5 \%$ and $1.0 \%$ by weight of soil was used and the effect of fiber reinforcement on shear strength parameters of sand was investigated. The experimental study mainly consists of direct shear tests that are conducted unreinforced and reinforced sand samples prepared at a relative density of $65 \%$. The results indicate that fiber mixtures can improve the shear strength of sand. The experimental results reveal fiber inclusion affected the strength parameters of sand and both angles of internal friction and cohesion displayed a significant improvement with an increase in fiber content in the soil matrix. Based on the experimental results, the effect of homopolymer polypropylene fiber on shear strength parameters of dry, dense and poorly graded quartz sand was analyzed.
\end{abstract}

Keywords: Soil Improvement, Fiber Reinforced Sand, Direct Shear Test.

\section{Introduction}

Utilizing a tensile element within the soil mass, in order to improve the strength, has been employed for a long time. More than 3000 years ago, the Babylonians used to reinforce soil (Jha and Mandal) [1]. Since the 1970s, the use of geotextile as reinforcement has become more popular due to more satisfactory performance compared with metal reinforcement, which has been reported in several instances (Gray and Ohashi [2]. The beneficial effect of geosynthetic material is largely dependent on the form in which it is used as reinforcement. For example, same geosynthetic material, when used in planar layers or geocells or discrete fibers, comprising exactly the same quantity of material will give different strength improvements in different forms. This difference in strengths achieved is mainly due to the difference in mechanism of failure in the soil reinforced with the geosynthetic material in different forms. Geotextiles, as reinforcing materials, not only increase shear strength but also improve ductility and provide smaller loss of post-peak strength in the reinforced sand in comparison with unreinforced sand (Haeri et al.) [3]. In recent times, some studies have been performed using polymeric fibers (Nataraj and McManis) [4]; (Santoni et al.) [5], (Yetimoglu and Salbas) [6] (Tang et al.) [7]. It has been suggested that natural resources may provide superior materials for improving soil structure, based on their costeffectiveness and friendly environment aspects (Prabakar and Sridhar) [8]. Randomly distributed fiber-reinforced soils have recently attracted increasing attention in geotechnical engineering as a type of soil improvement. Discrete fibers are simply added and mixed with the soil, much like cement, lime, or other additives. Randomly distributed fibers offer strength isotropy and limit potential planes of weakness that can develop in parallel to oriented reinforcement (Yetimoglu and Salbas,) [6]. Noorzad and Ghoreyshi Zarinkolaei [9] performed laboratory triaxial and direct shear tests to determine the static stress-strain response of sands reinforced with discrete randomly distributed fibers. The test results revealed that in both direct shear test and triaxial tests, the addition of fibers improved shear strength parameters and also limited the amount of post-peak reduction in shear resistance. Eldesouky et al. [10], Wei Shao et al. [11] and Jin Liu et al. [12] studied the effects of reinforcement on strength behavior of sand. The results showed that the fiber inclusion improved the shear strength and dilation. 
The major aim of this paper is to present the results of direct shear tests on the reinforced dry sand with polypropylene fiber as a type of available geotextile. To achieve this, a series of direct shear tests were applied to investigate the effects of fiber content on the behavior of sand under different static loads. In this study, Homopolymer Polypropylene (HP) fiber has been chosen as the reinforcement material, and it was randomly included in the sandy soil at three different percentages of fiber contents of $0.1 \%, 0.5 \%$, and $1.0 \%$ by weight of soil.

\section{Test Materials and Method}

\subsection{Experimental Study}

The direct shear apparatus is employed to determine the shear strength of the tested specimens. The shear box has dimensions of $60 \times 60 \times 25 \mathrm{~mm}$. According to the targeted relative density, the natural void ratio is calculated. Knowing the total volume to be occupied and specific gravity of the sand, the required amount of sand is weighed with an accuracy of $0.1 \mathrm{~g}$. The samples prepared at a relative density about $65 \%$. In the direct shear test, three different fiber contents are tested at the certain rate as unreinforced, $0.1 \%, 0.5 \%$, and $1.0 \%$ fiber content by weight of soil sample. The effects of fiber inclusion on the shear strength parameters are compared using the test results of the direct shear test on dry samples. The laboratory testing program was performed in the Istanbul Technical University's Prof. Dr. Hamdi Peynircioğlu Soil Mechanics Laboratory.

\subsection{Test Materials}

\subsubsection{Sand}

The Akpinar sand is used in the experimental study. The sand is first washed through ASTM \# 10 sieve. According to the Unified Soil Classification System (USCS) with ASTM D2487 (ASTM, 2007), the sand has been classified as SP. The constant head permeability test is conducted at the Istanbul Technical University, Civil Engineering Faculty, and Construction Materials Laboratory has conducted an analysis of the Akpinar sand. The results obtained from the binocular microscopes showed that sand particles are clean and semi-circular, semi-angular shaped. The composition mainly consists of quartz and it includes magnetite in small amounts. The grain size distribution of Akpinar sand is shown in Fig. 1. Moreover, the parameters of the sand are shown in Table 1. Fig. 2 illustrates the sand which used in this survey.

Table 1: Properties of sand.

\begin{tabular}{|l|r|}
\hline Property & value \\
\hline Specific Gravity & 2.69 \\
\hline Maximum void ratio & 0.876 \\
\hline Minimum void ratio & 0.547 \\
\hline Permeability $(\mathrm{m} / \mathrm{sec})$ & $2.371 \times 10^{-4}$ \\
\hline Effective grain size D10 $(\mathrm{mm})$ & 0.22 \\
\hline D60 $(\mathrm{mm})$ & 0.35 \\
\hline D30 $(\mathrm{mm})$ & 0.27 \\
\hline Coefficient of uniformity $\mathrm{Cu}$ & 1.6 \\
\hline Coefficient of Gradation $\mathrm{Cc}$ & 0.95 \\
\hline
\end{tabular}




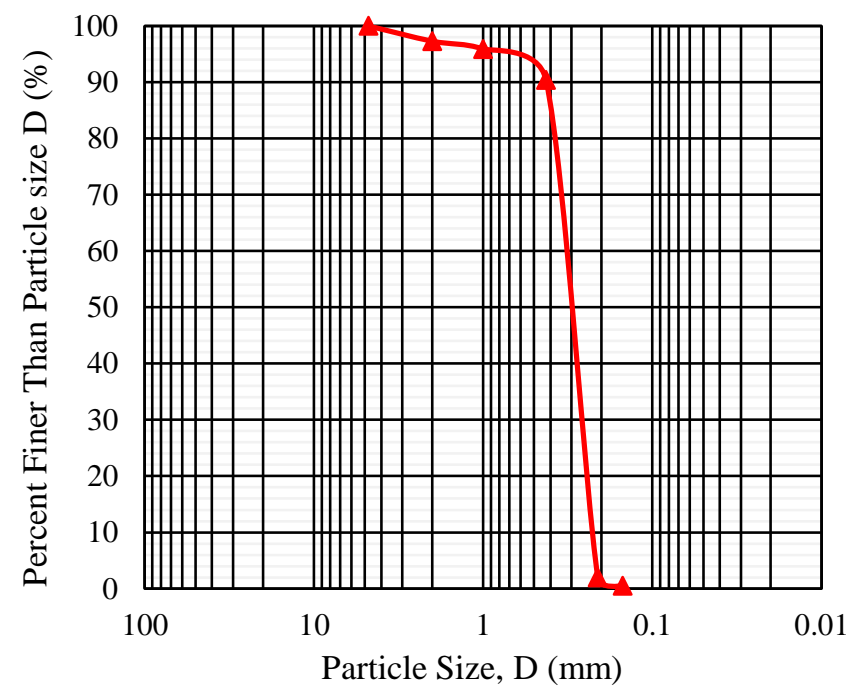

Fig. 1: Grain size distribution of the sand.

\subsection{Polypropylene Fiber}

The fiber, which was used in this research is homopolymer polypropylene (HP). It is made of pure homopolymer polypropylene. This fiber is used in concrete reinforcement to reduce plastic and settlement shrinkage. The homopolymer polypropylene fiber sample that was used for the study is FORTA Mighty-Mono Monofilament Microfiber is shown in Fig. 3. Physical properties of the homopolymer polypropylene fiber have been shown in Table 2 .

Table 2: Physical properties of HP fiber.

\begin{tabular}{|l|l|}
\hline Properties & Value \\
\hline Material & Virgin Homopolymer Polypropylene/Polypropylene \\
\hline Form & Monofilament Fiber \\
\hline Specific Gravity & 0.91 \\
\hline Absorption & Nil \\
\hline Tensile Strength & $83-96 \mathrm{ksi}(570-660 \mathrm{MPa})$ \\
\hline Length & $0.591^{\prime \prime}(15 \mathrm{~mm})$ \\
\hline Color & White \\
\hline Acid/Alkali Resistance & Excellent \\
\hline Compliance & ASTM C-1116 \\
\hline
\end{tabular}

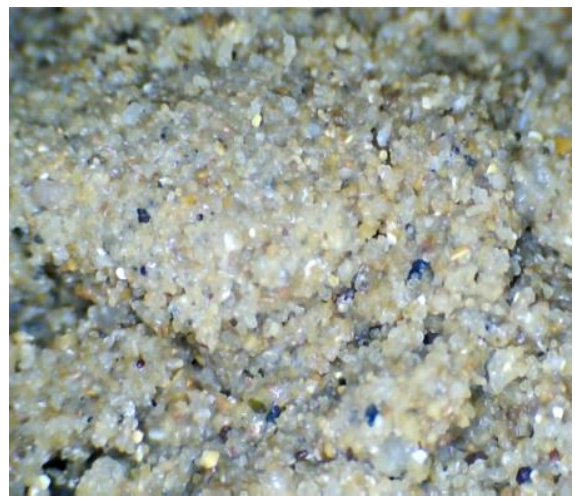

Fig. 2: Akpinar sand sample. 


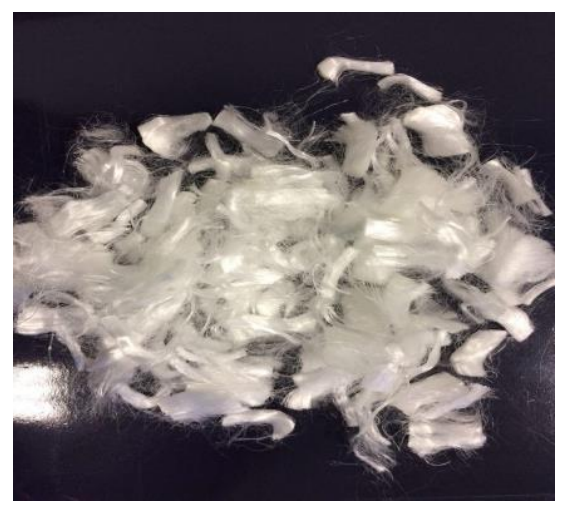

Fig. 3: HP fiber.

\section{Specimen Preparation and Shear Strength Experiment}

The Direct shear test is performed to determine the effects of fibers on the shear strength parameters of sand. The test was conducted on samples of $60 \times 60 \times 25 \mathrm{~mm}$ rectangular cube, having a relative density of $65 \%$. The amount of fiber added to the sand was taken as a percentage of the dry weight of sand. The fibers are accepted as part of the sand skeleton. The fiber content tested are $=0.1 \%, 0.5 \%$ and $1.0 \%$. For sample preparation, fibers were separated to enable a uniform mixture and they were mixed with sand in the pan by hand. Then, admixtures were put in the shear box tamping slightly with a spoon in five layers and compacted slightly to achieve a uniform sample. The porous papers are placed before and after the sample in the shear box mold of apparatus.

The normal stresses of $\sigma_{\mathrm{n}}=100,200$ and $300 \mathrm{kPa}$ are applied at unreinforced and reinforced sand samples and the loading rate was $0.12 \mathrm{~mm} / \mathrm{min}$ for all tests. The settlement is recorded for 15 minutes after the sample is loaded. Shear stress was recorded as a function of horizontal displacement up to a total displacement of $12 \mathrm{~mm}$ in order to observe the post-failure behavior. The shear stress-horizontal displacement curves and comparison between unreinforced and reinforced sand specimens under the same normal stresses of $\sigma_{\mathrm{n}}=100,200$ and $300 \mathrm{kPa}$ according to fiber content are presented in Fig. 4a to 4c respectively. 

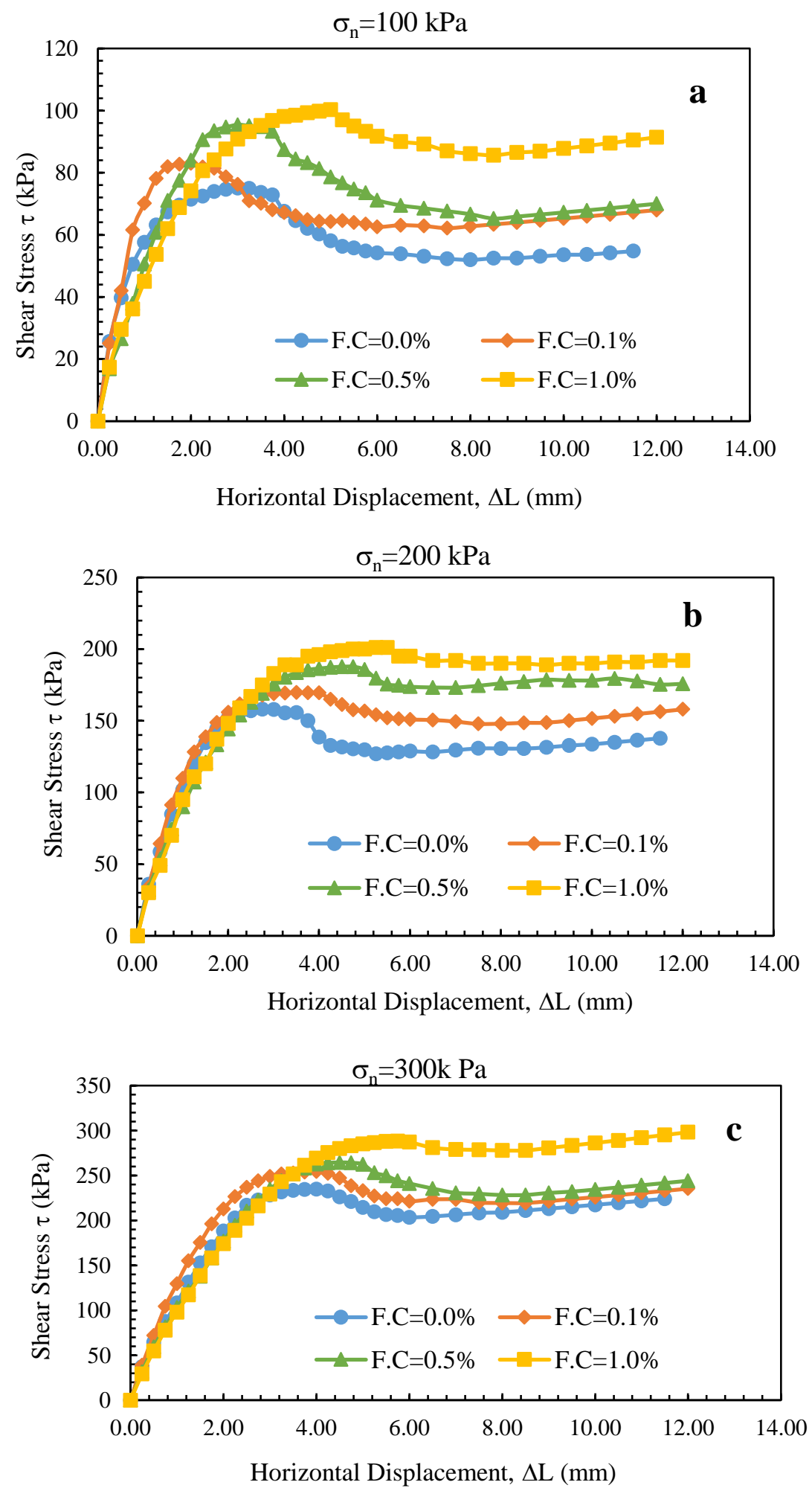

Fig. 4: Shear stress-horizontal displacement response for unreinforced and reinforced sand with different fiber content at the normal stresses: a vertical normal stress $\sigma_{\mathrm{n}}=100 \mathrm{kPa}$; b vertical normal stress $\sigma_{\mathrm{n}}=100 \mathrm{kPa} ; \mathbf{c}$ vertical normal stress $\sigma_{\mathrm{n}}=300 \mathrm{kPa}$. 
The results of the experimental study show an increase in shear strength of sand due to fiber reinforcement. As the fiber content increase, the peak, and residual shear strength increase significantly. Although, the Fig. 4 shows that fiber reinforcement is more effective for samples at low vertical normal stresses. This finding is consistent with the results of past studies which done by Wei Shao et al. [11].

In the same study, Wei Shao et al. performed directs shear test to evaluate the effect of randomly distribute fiber on shear strength parameters of sand. The study showed that inclusion of fiber yields an increase in shear strength value of sand. The investigation revealed that the peak shear stress increased gradually with an increase in the amount of fiber in the sand. Table 3 and Table 4 present information about the rate of increase and shear strength values of the present study and study of Wei Shao et al. [11]. The tables display that the rate of increase in the shear strength of fiber-reinforced sand mixtures increase with fiber content and drops under higher normal stresses.

Table 3: Summary of peak shear strength. (Present Study).

\begin{tabular}{|l|l|l|l|l|l|l|}
\hline Fiber content & \multicolumn{2}{|l|}{ Normal stress $100 \mathrm{kPa}$} & \multicolumn{2}{l|}{ Normal Stress 200 kPa } & \multicolumn{2}{l|}{ Normal Stress 300 kPa } \\
\hline & $\begin{array}{l}\text { Peak Shear } \\
\text { Stress }(\mathrm{kPa})\end{array}$ & Increase Rate & $\begin{array}{l}\text { Peak Shear } \\
\text { Stress }(\mathrm{kPa})\end{array}$ & Increase Rate & $\begin{array}{l}\text { Peak Shear } \\
\text { Stress }(\mathrm{kPa})\end{array}$ & Increase Rate \\
\hline 0 & 75 & 1 & 179 & 1 & 235 & 1 \\
\hline 0.1 & 86 & 1.15 & 183 & 1.02 & 261 & 1.11 \\
\hline 0.5 & 95 & 1.27 & 193 & 1.08 & 270 & 1.15 \\
\hline 1.0 & 100 & 1.33 & 201 & 1.12 & 288 & 1.23 \\
\hline
\end{tabular}

Table 4: Summary of peak shear strength. (Wei Shao et al. 2014).

\begin{tabular}{|l|l|l|l|l|l|l|}
\hline Fiber content & \multicolumn{2}{|l|}{ Normal stress 50 kPa } & \multicolumn{2}{l|}{ Normal Stress 150 kPa } & \multicolumn{2}{l|}{ Normal Stress 200 kPa } \\
\hline & $\begin{array}{l}\text { Peak Shear } \\
\text { Stress (kPa) }\end{array}$ & Increase Rate & $\begin{array}{l}\text { Peak Shear } \\
\text { Stress (kPa) }\end{array}$ & Increase Rate & $\begin{array}{l}\text { Peak Shear } \\
\text { Stress (kPa) }\end{array}$ & Increase Rate \\
\hline 0 & 28 & 1 & 104 & 1 & 140 & 1 \\
\hline 0.1 & 36 & 1.29 & 104 & 1 & 150 & 1.07 \\
\hline 0.3 & 41 & 1.46 & 121 & 1.16 & 166 & 1.19 \\
\hline 0.6 & 52.5 & 1.88 & 128 & 1.23 & 185 & 1.32 \\
\hline 0.9 & 65 & 2.32 & 145 & 1.39 & 210 & 1.5 \\
\hline
\end{tabular}

\section{Effects of Fiber on Shear Stress of Dense Sand}

The shear stress of unreinforced and reinforced sand at peak point $\tau_{\mathrm{p}}$ and residual point $\tau_{\mathrm{r}}$ values are determined by direct the shear box test. The peak shear stress and residual shear stress are calculated under the normal stresses of $100 \mathrm{kPa}, 200 \mathrm{kPa}$, and $300 \mathrm{kPa}$ for samples with $0.0 \%, 0.1 \%, 0.5 \%$ and $1.0 \%$ fiber content. The results of the shear stress of the direct shear box test are shown in Fig. 5a and 5b. According to the results, the randomly distributed fiber addition affected the shear strength parameters of sand. As the fiber content increased, there has been an increase in shear stress values of reinforced sand with respect to the normal stress.

With respect to the Fig. 5 and Table 3 it can be observed that there is an increase in shear stress of sand. The peak shear stress of $75 \mathrm{kPa}$ for the unreinforced sample under $100 \mathrm{kPa}$ shear force illustrated a $25 \%$ increase and for samples under $200 \mathrm{k} \mathrm{Pa}$ and $300 \mathrm{kPa}$ increasing ratio is $11 \%$ and $18 \%$ respectively at the peak point. These values for residual shear stress under $100 \mathrm{kPa}, 200 \mathrm{kPa}$, and $300 \mathrm{kPa}$ showed improvement of 40\%, 28\%, and 24\% respectively. With respect the result, it can be concluded that shear strength of sand under low normal stress shows a greater value compared with greater normal stresses. 

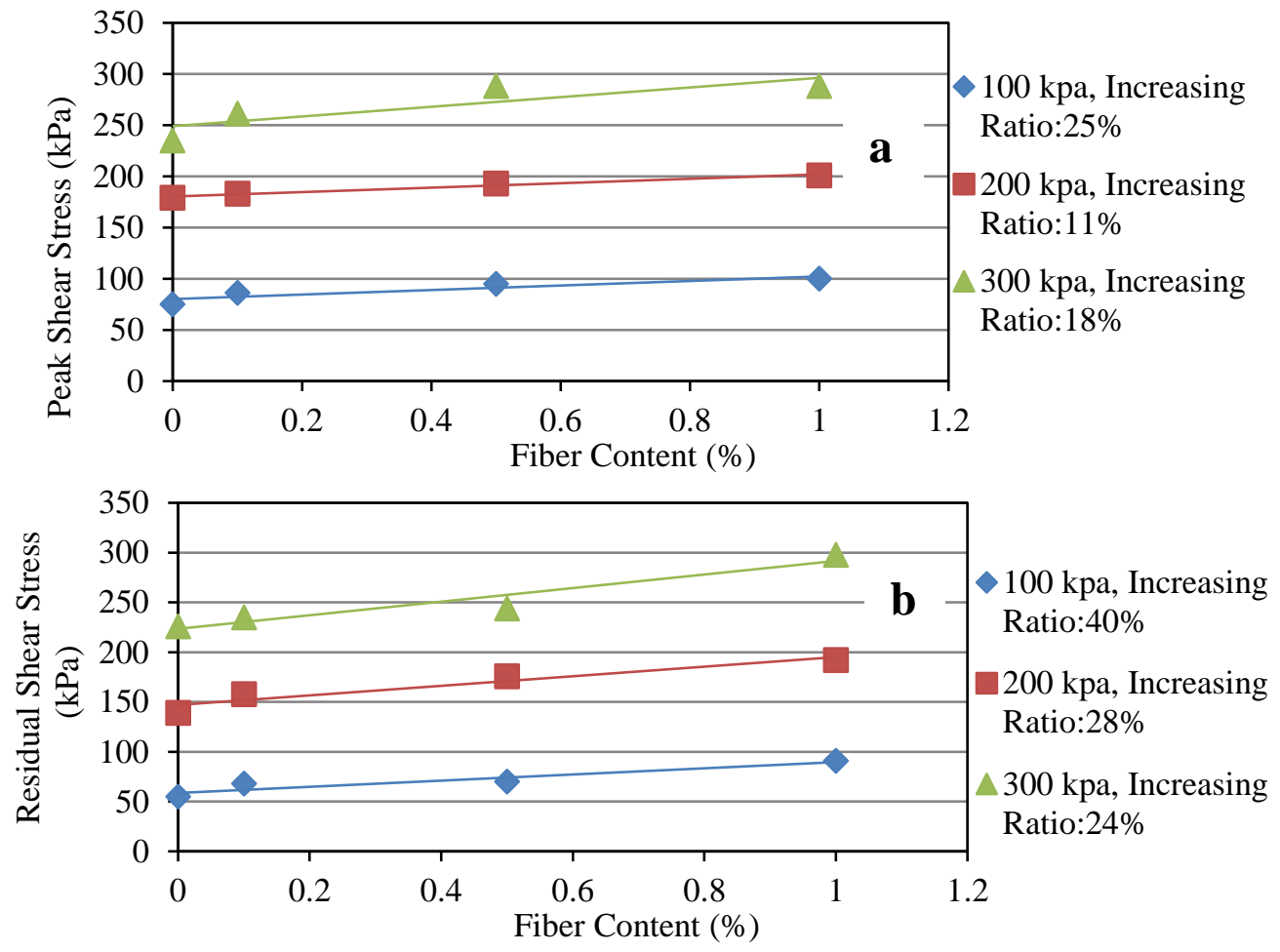

Fig. 5: Peak and residual shear stress of unreinforced and reinforced sand versus fiber content: Peak shear stress (a); residual shear stress $(\mathbf{b})$.

\section{Effects of Fiber on Peak and Residual Shear Strength Angle and Cohesion}

In the direct shear test, the angle of internal friction at peak and residual points $\left(\phi_{\mathrm{p}}, \phi_{\mathrm{r}}\right)$ and apparent cohesion $C_{a}$ parameters are calculated by linear regression analysis with correlation coefficients that are approximately equal to unity $\mathrm{R}^{2}=0.97-0.999$.
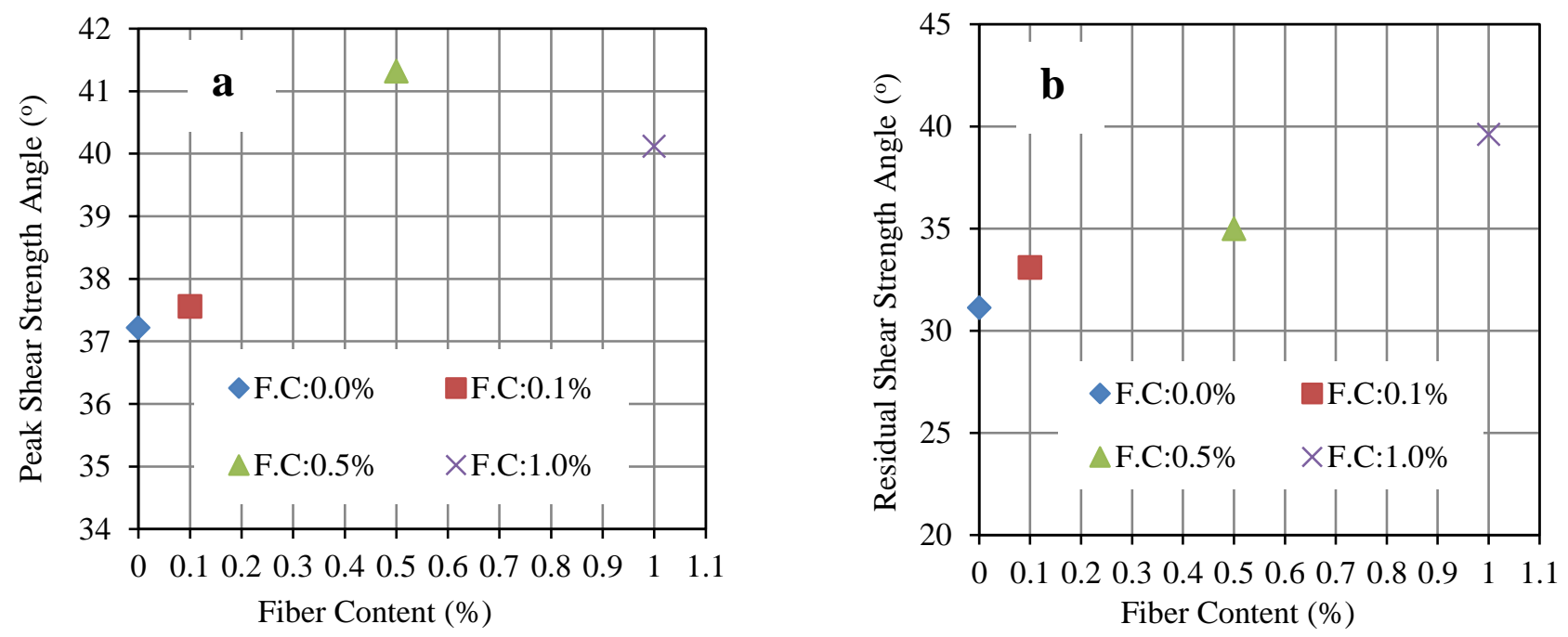

Fig. 6: The peak shear strength angle $\phi_{\mathrm{p}}(\mathbf{a})$, and the residual shear strength angle $\phi_{\mathrm{r}}(\mathbf{b})$. 
The peak shear strength angle $\phi_{\mathrm{p}}$ and residual shear strength angle $\phi_{\mathrm{r}}$ were calculated from the direct shear test are presented in Fig. 6a and Fig. 6b, respectively. It is presented that changes in peak shear strength angle and residual strength angle values change between $37.22^{\circ}-40.34^{\circ}$ and $31.13^{\circ}-39.62^{\circ}$ for peak and residual shear strength angle respectively.

As shown in Fig. 7a and Fig. 7b, apparent cohesion of unreinforced and reinforced sand can be calculated with respect to the normal stress and shear stress curves. There is no evidence of an increase in the cohesion value for the unreinforced samples in the peak point, but with the increase in the amount of fiber content up to $0.1 \%, 0.5 \%$ and $1.0 \%$ it can be seen that there is cohesion for the samples equal to $12.80 \mathrm{kPa}, 18.7 \mathrm{kPa}$, and 3.341 for samples with $0.1 \%, 0.5 \%$ and $1.0 \%$ fiber content respectively. It can be concluded that fiber addition affects the apparent cohesion of sand and in samples with more fiber content, and with an increase of the fiber content by about $1.0 \%$ both the cohesion and angle of internal friction getting smaller.
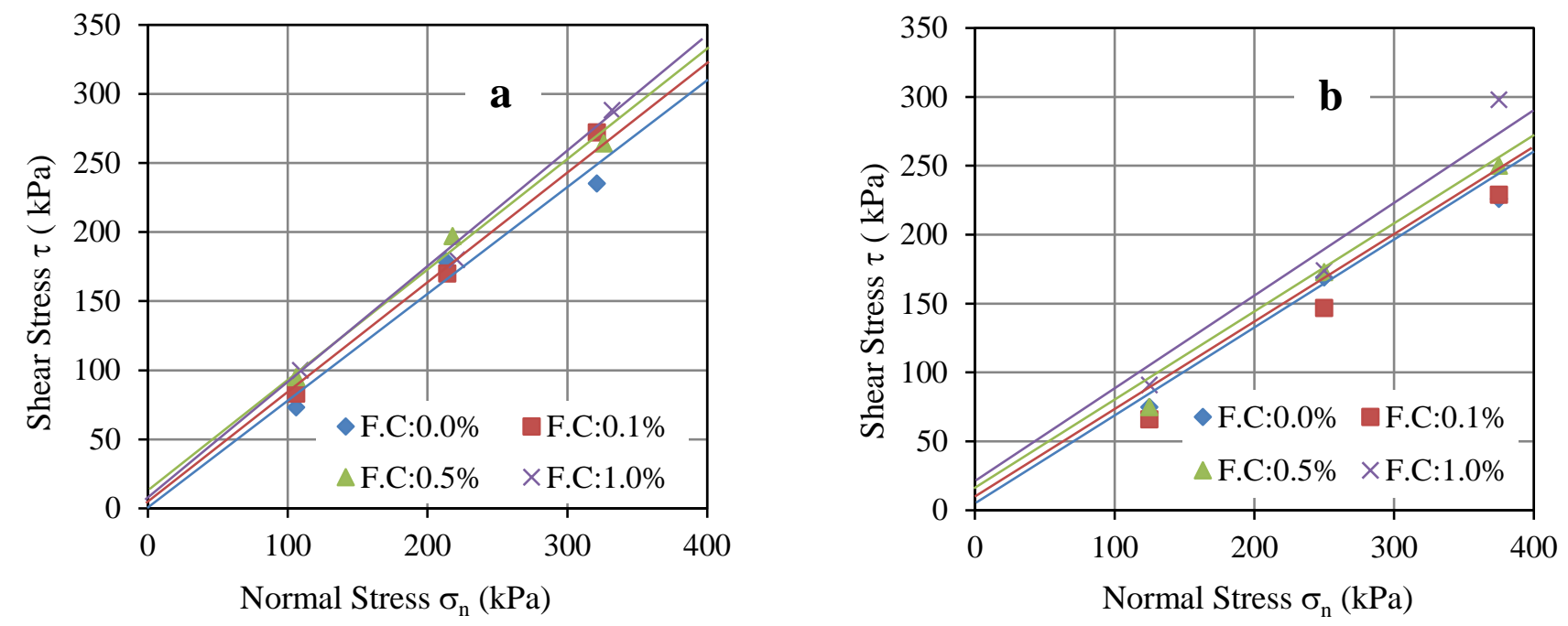

Fig. 7: Peak and residual shear stress and apparent cohesion values according to fiber content: Peak point (a); Residual point (b).

The experimental results demonstrate that for sand reinforced with different content of HP fiber, both angles of internal friction and cohesion have exhibited a considerable increase with an increase in the amount of fiber in the soil matrix. These results are consistent with the results of the previous study which was done by Wei Shao et al. [11]. The angle of internal friction and cohesion values obtained from the linear regression analysis for different fiber reinforcement percentages for the present study and study of Wei Shao et al. [11] are summarized in Table 5 and Table 6.

Table. 5: Shear strength parameters of fiber-reinforced sand. (Present study).

\begin{tabular}{|l|l|l|l|}
\hline Sample No & $\begin{array}{l}\text { Fiber } \\
\text { Content }(\%)\end{array}$ & $\begin{array}{l}\text { Cohesion } \\
(\mathrm{kPa})\end{array}$ & $\begin{array}{l}\text { Angle of } \\
\text { internal } \\
\text { friction } \\
\text { (degree) }\end{array}$ \\
\hline 1 & 0 & 0 & 37.22 \\
\hline 2 & 0.1 & 12.8 & 37.56 \\
\hline 3 & 0.5 & 18.7 & 41.32 \\
\hline 4 & 1.0 & 3.3 & 40.12 \\
\hline
\end{tabular}


Table. 6: Shear strength parameters of fiber-reinforced sand. (Wei Shao et al. 2014).

\begin{tabular}{|l|l|l|l|}
\hline Sample No & $\begin{array}{l}\text { Fiber } \\
\text { Content }(\%)\end{array}$ & $\begin{array}{l}\text { Cohesion } \\
(\mathrm{kPa})\end{array}$ & $\begin{array}{l}\text { Angle of } \\
\text { internal } \\
\text { friction } \\
(\text { degree })\end{array}$ \\
\hline 1 & 0 & 3.5 & 29.8 \\
\hline 2 & 0.1 & 8.8 & 31.8 \\
\hline 3 & 0.3 & 16.3 & 33.8 \\
\hline 4 & 0.6 & 21.5 & 35.4 \\
\hline 5 & 0.9 & 30.9 & 37.1 \\
\hline
\end{tabular}

\section{Discussion}

The unreinforced sand has insignificant or zero cohesion between soil particle resulting in its structure. The fiber reinforcement mechanism in sand generally includes that the fiber and sand particles constrain each other to produce interface force. The conducted study on unreinforced and fiber-reinforced sand enable exploring the shear strength behaviors of fiber-reinforced sand in a detailed way. The stress-strain relationship is prominent to identify the mechanical behavior of modified soils. (Heineck et al.) [13]. However, through the studying the shear stress-strain curves, a better understanding can be developed as to how the fiber reinforcement effects the mechanical behaviors of sandy soils. It is important that the efficacy of the inclusion of fibers into the soil is greatly affected by the amount of fiber. (Gray and AlRefaei) [14], (Maher and Ho) [15], (Consoli et al.) [16]. Furthermore, amount of confining pressure that is applied on fiberreinforced sand has a direct impact on the shear strength parameters of the soils which are blended by fibers. (Wei Shao et al.) [11]. Therefore, this research is focused on determining the effects of various fiber content and different confining pressure on shear strength parameters of poorly graded quartz sand. The generally sand materials were prepared with three different fiber content of $0.1,0.5$ and $1.0 \%$ by weight of sand and tested at normal stresses of 100, 200 and $300 \mathrm{kPa}$ in the shear box test. Fig. 4 show the shear stress-strain curves of the unreinforced and fiber-reinforced sand under the three different normal stresses. As shown in the Fig. 4 the presence of fiber affected the trend of stress-strain curves. The stressstrain curves of sand reinforced with various ratios of polypropylene fibers displayed the similar change trends at the same vertical normal stress. With respect to this figure in the shearing period, the shear strength of reinforced samples increased gradually. In order to evaluate the effect of fiber on the shear strength of the sand a strength ratio parameter is introduced and defined as

$$
R_{s p}=\frac{\tau_{p}^{R}}{\tau_{p}}
$$

Where $\tau_{p}^{R}$ and $\tau_{p}$ are stresses of fiber-reinforced and unreinforced sand at the peak point, respectively. As regards to this definition, the variation shear strength ratio with normal stress under different experimental normal stresses can be calculated. Fig. 8, shows that the rate of fiber-reinforced sand samples grows with fiber content and decreases under higher confining pressure. For fiber-reinforced sand specimens, the greater the fiber contents of reinforced sand, the greater the shear strength ratio of reinforced sand at the same normal stress. Furthermore, the shear strength ratio of reinforced sand dropped with the improvement of vertical normal stress from 100 to $200 \mathrm{kPa}$. The shear strength ratio is observed to be as high as 1.33 for reinforced sand specimen prepared with a fiber content of $\rho=1.0 \%$ at a normal stress of $100 \mathrm{kPa}$ and decreased about 1.12 at a normal stress $200 \mathrm{kPa}$. For specimens with fiber contents of $\rho=0.1$ and $0.5 \%$, the shear strength ratio varied from 1.15 and 1.27 to 1.11 and 1.12 between normal stresses from 100 to $300 \mathrm{kPa}$. However, the results showed the shear strength ratio increased slightly with the increase of vertical normal stress from 200 to $300 \mathrm{kPa}$. This finding is consistent with the result of the previous researches. (Gray and Al-Refaei) [14], (Dos Santos et al.) [17], (Wei Shao et al.) [11]. Therefore, the fiber reinforcement is more effective for specimens under low vertical normal stress. Normally, it is expected to display opposite trends between two strength parameters, the angle of internal friction and cohesion of soil. For example, when the angle of friction arises, the cohesion of soils generally reduces. However, the 
inclusion of the fibers causes an improvement in cohesion. The improvement in the angle of internal friction is most probably associated with mobilization of friction between the soil particles and fibers. (Wei Shao et al.) [11], (Gao and Zhao) [19], Yetimoğlu and Salbas) [6]. On the other side, improvement of ductility of soil through the stretching of the fiber causes to increase the cohesion. (Kumar et al.) [20], Consoli et al. [21] and [22]. Fibers are the major components in the fiber-sand composites which has a great influence on the improvement of coherent values. The existence of fibers into the sand is providing apparent cohesion that contributes to the shear strength. This detection is expected with the results of the previous studies. (Shukla et al.) [23] (Wei Sho et al.) [11].

Because of the extensible nature of the fibers, they are stretched in the soil matrix during the shearing process, so they cause the sand to behave like cohesive soils, increasing the tension resistance of fiber-reinforced sand which finally increase the shear strength. (Consoli et al.) [24], (Gao and Zhao) [19], (Wei Sho et al.) [11]. The randomly distributed discrete fibers may act as a three-dimensional structure to interlock sand particles, forming the grains as a unitary coherent matrix that helps to restrict the displacement. It is speculated that the furrows and pits that formed on the fiber surface constituted an interlock and improved the interaction between sand matrix and polypropylene fiber surface. The interlocking effect increases with an increased fiber content, that is one of the significant reasons causing an improvement in the shear strength of specimens with high fiber contents. The Fig. 9 shows an image of the fiber-reinforced specimen at the end of a direct shear test.

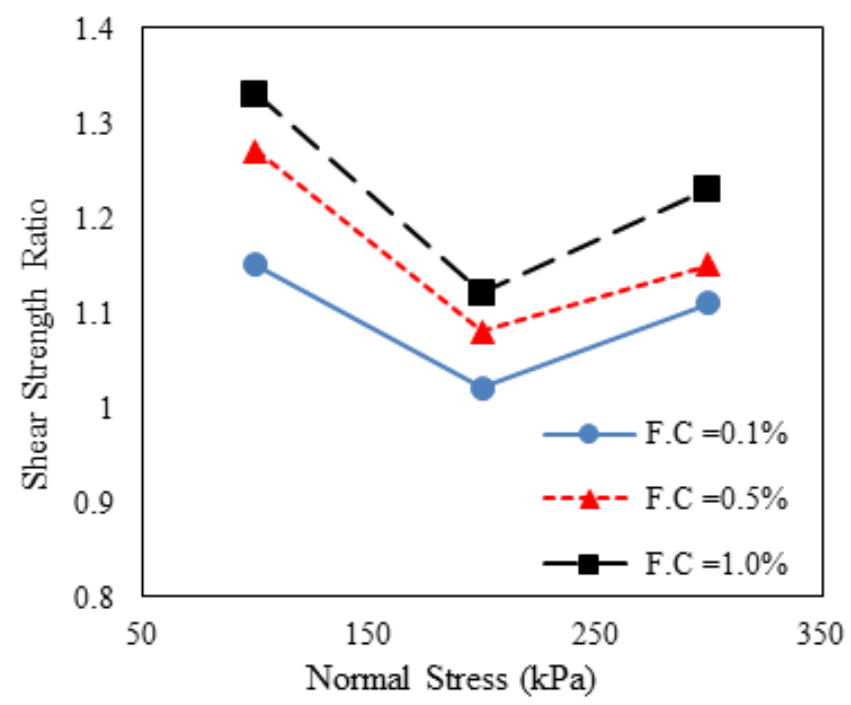

Fig. 8: Peak shear strength ratio versus normal stress.

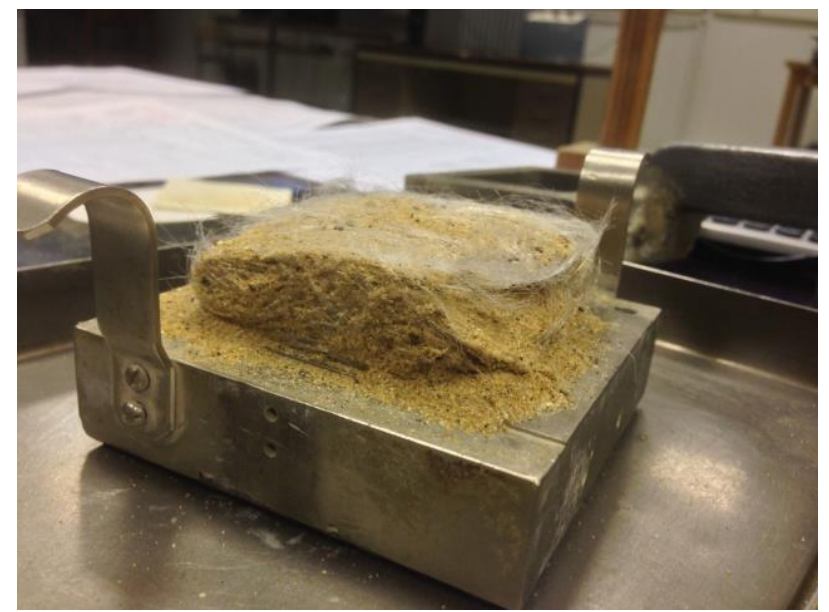

Fig. 9: deformation of fiber-reinforced specimen at the end of the test. 
With respect to the Fig. 9, it can be seen that fibers in the soil matrix act as a structural network to interlock sand particles. However, it is thought that the fiber content is not the only effective factor on shear strength parameters of soils. In this study unreinforced and fiber-reinforced sand samples prepared with a relative density of $65 \%$. Previous studies were done by researchers showed that relative density has a significant effect on the shear stress-strain behavior of fiberreinforced sand. M. Eldesouky et al. [10] studied the effect of the fiber inclusion and relative density on the shear strength of the dry sand samples. The results showed that increase of the fiber content from $0.0 \%$ to $1.0 \%$ improves the normalized shear strength of dry sand in both peak and residual points by about $25 \%-30 \%$ while increasing the relative density from the $25 \%$ to $90 \%$ improves the peak shear strength unreinforced and reinforced.

However, this study aims at conducting an experimental study on the effect of polypropylene fiber on the shear strength behavior of poorly graded quartz sand and the determination of fiber length and fiber types on shear strength parameters of sandy soils need further investigation.

\section{Conclusion}

In this study, the effects of reinforcement on shear strength parameters of dense sand were evaluated and homopolymer polypropylene fiber was used as a reinforcement material. Three different percentage of fiber $(0.1 \%, 0.5 \%$ and $1.0 \%$ of dry weight of soil) were used in the laboratory tests and behavior of randomly distributed fiber reinforced dense sand under shear box test was studied. According to the results, the shear strength of reinforced sand samples was improved as fiber content increases and these results showed maximum improvement percentage of $25 \%$ for samples under $100 \mathrm{kPa}$ shear force at peak point and a maximum improvement of $40 \%$ for the sample under $100 \mathrm{kPa}$ at the residual point. As per the results, as fiber content increased, the angle of internal friction improved. Also, the amount of apparent cohesion of reinforced sand samples was calculated for both peak and residual points. It was concluded that there is no apparent cohesion for the plain sand while for samples with $0.1 \%, 0.5 \%$ and $1.0 \%$ fiber content, an improvement in the amount of apparent cohesion was observed.

In order to investigate the effect of fiber on the shear strength of the fiber-reinforced sand, strength ratio $\left(R_{s p}\right)$ was introduced. For fiber-reinforced sand, the greater the reinforced sand, the greater the shear strength ratio of reinforced sand at the same vertical normal stress. For the same reinforcement material, the shear strength ratio of reinforced sand decreased with the improvement of vertical normal stress from 100 to $200 \mathrm{kPa}$, and then the shear strength ratio grew slightly with the increase of normal stress from 200 to $300 \mathrm{kPa}$. For sand reinforced with different fiber content, cohesion has exhibited a significant increase in the improvement of fiber content while the angle of internal friction increases slightly.

In conclusion, the randomly distributed homopolymer polypropylene fiber inclusion improved the shear strength of sand considerably. The results obtained from the experimental study are also consistent with the previous studies that are conducted on randomly distributed polypropylene fiber reinforced sands. It should be observed that the results of this survey are valid only for the materials used in this work. The experiments were done while the type of sand and fiber were kept constant. The orientation of the fibers was not considered. Further investigations are needed with different types of soils, different fiber lengths, different types of fiber (synthetics and natural fibers), different aspect ratios and orientation of the fibers to completely investigate the effect of fiber inclusion to the soils.

\section{References}

[1] K. Jha, \& J. N. Mandal, "A review of research and literature on the use of geosynthetics in the modern geotechnical world," pp. 85-93, 1988.

[2] D. H. Gray, and H. Ohashi, "Mechanics of fiber reinforced in sand," Journal of Geotechnical Engineering, ASCE, vol. 109, no. 3, pp. 335-353, 1983.

[3] S. M. Haeri, R. Noorzad, A. M. Oskoorouchi, "Effect of geotextile reinforcement on the mechanical behavior of sand," Geotextiles and Geomembranes, vol. 18, no. 6, pp. 385-402, 2000. DOI:10.1016/S0266-1144(00)00005-4,

[4] M. S. Nataraj, and K. L. Mcmanis., "Strength and Deformation Properties of Soils Reinforced with Fibrillated Fibers,"Journal of Geosynthetic International, vol. 4, no. 1, pp. 65-79, 1997.

[5] R. L. Santoni, J. S. Tingle, S. L. Webster, "Engineering properties of sand-fiber mixtures for road construction," Journal of Geotechnical and Geoenvironmental Engineering, ASCE, vol. 127, pp. 258-268, 2001. 
[6] T. Yetimoglu, and O. Salbas, "A study on shear strength of sands reinforced with randomly distributed discrete fiber," Geotextiles and Geomembranes, vol. 21, no. 2, pp. 103-110, 2003.

[7] C. Tang, B. Shi, W. Gao, F. Chen, and Y. Cai, "Strength and mechanical behavior of short polypropylene fiber reinforced and cement stabilized clayey soil," Geotextiles and Geomembranes, vol. 25, no. 3, pp. 194-202, 2007.

[8] J. Prabakar, R. S. Sridhar, "Effect of random inclusion of sisal fiber on strength behavior of soil," Journal of Construction and Building Materials, vol. 16, pp. 123-131, 2002.

[9] R. Noorzad, and S. T. Ghoreyshi Zarinkolaei, "Comparison of mechanical properties of fiber-reinforced sand under triaxial compression and direct shear test," DE Gruyter open, Open Geosci., vol. 1, pp. 547-558, 2015.

[10] H. M. Eldesouky, M. Ky, M. M. Morsy, M. F. Mansour, "Fiber reinforced sand strength and dilation characteristics," Ain Shams Engineering Journal, vol. 7, pp. 517-526, 2016.

[11] W. Sho, B. Cetin, Y. Li., J. Li., L. Li., "Experimental investigation of mechanical properties of sands reinforced with discrete randomly distributed fiber," Geotechnical and Geological Engineering, vol. 32, pp. 901-910, 2014.

[12] J. Liu, Q. Feng, Y. Wang, Y. Bai, Jihongwei, and Z. Song, "The effect of polymer-fiber stabilization on the unconfined compressive strength and shear strength of sand," Journal of Advances in Materials Science and Engineering, p. 9, 2017.

[13] K. S. Heineck, M. R. Coop, N. C. Consoli, "Effect of microrefinement of soils from very small to large shear strains," Journal of Geotechnical Geoenvironmental Engineering, ASCE 13, vol. 1, no. 8, pp. 1024-1033, 2005.

[14] D. H. Gray, T. Al-Refaei, "Behavior of fabric-versus fiber-reinforced sand," Journal of Geotechnical Engineering, ASCE, vol. 112, no. 8, pp. 804-820, 1986.

[15] M. H. Maher, D. H. Gray, "Static response of sand reinforced with randomly distributed fibers," Journal of Geotechnical Engineering, vol. 116, no. 11, pp. 1661-1677, 1990.

[16] N. C. Consoli, F. Zortea, F. L.de Souza M, "Studies on the dosage of fiber-reinforced cemented soils," Journal of Materials in Civil Engineering, ASCE, vol. 23, no. 12, pp. 1624-1632, 2011.

[17] A. P. S. Dos Santos, N. C. Consoli, B. A. Baud, “The mechanics of fiber-reinforced sand," Journal of Geotechnique, vol. 60, no. 10, pp. 791-799, 2010.

[18] Z. Gao, J. Zhao, "Evaluation on failure of fiber-reinforced sand," Journal of Materials in Civil Engineering., ASCE vol. 139, no. 1, pp. 95-106, 2013.

[19] R. Kumar, V. K. Kanaujia, D. Chandra, "Engineering behavior of fiber-reinforced pond ash and silty sand," Geosynthetics International., vol. 6, no. 5, pp. 509-518, 1999.

[20] N. C. Consoli, M. A. Vendruscolo, A. Fonini, F. D. Rosa, "Fiber reinforcement effects on sand considering a wide cementation range," Journal of Geotextile and Geomembrane, vol. 27, pp. 196-203, 2009.

[21] N. C. Consoli, L. Festugato, K. S. Heineck, "Strain-hardening behavior of fiber-reinforced sand in view of filament geometry," Geosynthetics International, vol. 16, no. 2, pp. 109-115, 2009.

[22] S. K. Shukla, N. Sivakugan, A. K. Singh, "Analytical model for fiber-reinforced granular soils under high confining stresses," Journal of Materials in Civil Engineering, ASCE, vol. 22, no. 9, pp. 935-942, 2010.

[23] N. C. Consoli, M. B. Corte, L. Festugato, "Key parameter for tensile and compressive strength of fiber-reinforced soil-lime mixtures," Geosynthetics International, vol. 19, no. 5, pp. 409-414, 2012. 